\title{
Home Care Pharmacy Practice in Canada: A Cross-Sectional Survey of Services Provided, Remuneration, Barriers, and Facilitators
}

\author{
Sherilyn Houle and Linda MacKeigan
}

\begin{abstract}
Background: As the population ages, and individuals desire to remain in their homes as long as possible, the need for in-home care is expected to increase. However, pharmacists have rarely been included in studies of in-home care, and little is known about the prevalence or effectiveness of pharmacists' home-based services in Canada.

Objective: To identify pharmacy practices in Canada that regularly provide in-home patient care and to identify specific services provided, remuneration obtained, and barriers and facilitators influencing the provision of home-based care.

Methods: A link to a web-based survey was posted in e-newsletters of provincial, territorial, and national pharmacy associations in Canada. In addition, pharmacists known to the researchers as providing in-home clinical services were contacted directly. The survey was open from October to December 2015. Practices or organizations that performed at least one home visit per week for clinical purposes, with documentation of the services provided, were eligible to participate. One response per practice or organization was allowed.
\end{abstract}

Results: Seventeen practices meeting the inclusion criteria were identified, representing community, hospital, and clinic settings. Home visits were most commonly performed for individuals with complex medication regimens or nonadherence to medication therapy. The most common services were conducting medication reconciliation and reviews and counselling patients about medication adherence. No practices or organizations billed patients for these services, yet lack of remuneration was an important barrier identified by many respondents. Although 12 (71\%) of the respondents collected data for evaluative purposes, collection of clinical or health system outcome data was rare.

Conclusions: Few Canadian pharmacy practices that provide in-home patient care at least once a week could be identified. Data collection suitable to establish an evidence base for this service was infrequently performed by practices and organizations providing home-based care. Such evidence is needed to justify the expansion of this service nationally, including consistent and adequate remuneration from governments or other payers.

Keywords: home care services, pharmacists, pharmacy services

\section{RÉSUMÉ}

Contexte : Au fur et à mesure que la population vieillit et que les gens désirent rester le plus longtemps possible à leur domicile, on s'attend à une croissance des besoins de soins à domicile. Or, les pharmaciens ont rarement été inclus dans les études de soins à domicile et l'on connaît peu de choses sur la prévalence et l'efficacité des services de soins à domiciles prodigués par des pharmaciens au Canada.

Objectifs : Recenser les pharmacies au Canada qui prodiguent régulièrement des soins à domicile et déterminer précisément quels sont les services fournis, la rémunération obtenue et les éléments qui font obstacle ou facilitent la prestation de soins à domicile.

Méthodes : Un lien menant à un sondage en ligne a été inclus dans les infolettres d'associations provinciales, territoriales et nationales de pharmacie au Canada. De plus, les chercheurs ont communiqué directement avec les pharmaciens dont ils savaient qu'ils offraient des services cliniques à domicile. Le sondage était accessible d'octobre à décembre 2015. Les pharmacies ou les organismes qui faisaient au moins une visite à domicile par semaine à des fins cliniques et qui consignaient les services fournis étaient admissibles à l'étude. Une réponse par pharmacie ou par organisme était permise.

Résultats : Dix-sept pharmacies répondant aux critères d'inclusion ont été recensées. Elles provenaient de milieux communautaire, hospitalier et clinique. Les visites à domicile étaient le plus souvent faites auprès de personnes ayant une pharmacothérapie complexe ou n'observant pas le traitement médicamenteux. Les services les plus fréquents étaient : établir des bilans comparatifs des médicaments, procéder à des évaluations de la pharmacothérapie et offrir de l'information aux patients sur l'observance pharmacothérapeutique. Aucune pharmacie ou aucun organisme n'a facturé ces services aux patients; or, l'absence de rémunération représentait un des principaux obstacles selon bon nombre de répondants. Bien que $12(71 \%)$ des répondants aient recueilli des données à des fins d'évaluation, on effectuait rarement la cueillette de données sur les résultats cliniques ou du système de santé.

Conclusions : On a pu recenser que peu de pharmacies canadiennes qui offrent des soins à domicile aux patients au moins une fois par semaine. On a noté qu'on réalisait trop peu fréquemment la collecte de données permettant de fournir un fondement à ce service. De telles données probantes sont nécessaires pour justifier le fait d'étendre ce service à l'ensemble du pays et de dégager une rémunération uniforme et adéquate provenant des gouvernements ou d'autres payeurs.

Mots clés : soins à domicile, pharmaciens, services de pharmacie 


\section{INTRODUCTION}

$\mathrm{H}_{\mathrm{o}}^{\circ}$ ome care has been defined as "an array of services for people of all ages, provided in the home and community setting, that encompasses health promotion, teaching, curative intervention, end-of-life care, support, maintenance, social adaption, integration and support for family caregivers." In 2011, 1.4 million Canadians received home care, a 55\% increase since 2008. ${ }^{1}$ Despite this growth, almost half a million community-dwelling Canadians requiring home care assistance for the management of chronic health conditions, disability, or aging did not receive any home care in 2012, and $15 \%$ of those receiving support did not receive all the care they required. ${ }^{2}$

The Resident Assessment Instrument - Home Care (RAI-HC) is a tool "used by home care professionals to evaluate the strengths, preferences, and needs of home care clients in order to develop a care plan and allocate services."3 A 2010 crosssectional analysis of RAI-HC data for more than 125000 Ontario senior citizens receiving publicly funded, long-term (60 days or more) home care found that $40 \%$ of recipients were 75 years of age or older, and a high proportion had multimorbidity. ${ }^{3}$ Diabetes mellitus, dementia, stroke, chronic obstructive pulmonary disease, cancer, heart failure, and psychiatric illness were the most common medical conditions. Furthermore, RAI-HC data from similar populations in the Yukon, British Columbia, Manitoba, Ontario, and Nova Scotia showed that more than half of patients reported having pain, with $15 \%$ reporting severe pain. Also, nearly 1 in 5 had experienced a fall in the 90 days before their assessment. ${ }^{3}$ These indicators of the medical complexity of patients receiving long-term home care suggest that this population also has complex drug therapy. Indeed, regression analysis of the RAI-HC data showed that significant predictors of emergency department admission included falls, receiving an anxiolytic or antidepressant medication, and polypharmacy (defined as the use of 5 or more medications). ${ }^{4}$

Despite the above-noted risks of medication use in the longterm home care population, 2 meta-analyses comprising a total of 16 randomized trials concerning the effectiveness of in-home care revealed that pharmacists were rarely included as members of the home care teams studied.,5 A literature review of Englishlanguage reports of clinical pharmacy services in the home published between 1990 and 2007 identified 57 home-based clinical pharmacy programs, primarily in the United Kingdom, the United States, and Australia; however, $80 \%$ of these were within the context of a time-limited research project rather than an ongoing patient service. ${ }^{7}$ Medication review and medication management were the most common services provided by the pharmacists, with a focus on elderly patients and those deemed to be at high risk of complications from medication therapy. Hospital admission and health-related quality of life were the most commonly evaluated outcomes; however, of the 10 studies using these end points, only 3 assessing hospital admission and
2 assessing quality of life reported statistically significant results favouring the in-home intervention.

Recently, evaluations of pharmacist home visits provided under the Ontario MedsCheck at Home (medication review) program have been published; however, they involved a single pharmacist and/or a single community pharmacy and were largely descriptive in nature. ${ }^{89}$ A survey of pharmacist providers of homebased patient care in Canada, conducted in 1999, identified this as a rare practice. ${ }^{10}$ It is noteworthy that 12 of the 16 providers in that study were based in a community pharmacy. ${ }^{10}$ In 2008, the Canadian Society of Hospital Pharmacists (CSHP), in its goals and objectives for the CSHP 2015 initiative, ${ }^{11}$ advocated for the role of pharmacists in this area, with objective 2.3 calling for pharmacists to "manage medication therapy for patients with complex and high-risk medication regimens, in collaboration with other members of the healthcare team" in $85 \%$ of home care services nationwide. In contrast to the 1999 survey of community pharmacist-delivered home visits in Canada, ${ }^{10}$ results from the 2009/10 iteration of a longitudinal survey of Canadian hospital pharmacy managers identified that $38 \%$ of the respondents' hospitals provided a home care service, and of these, $48 \%$ utilized pharmacists as members of the care team for patients with complex and high-risk regimens. ${ }^{12}$ This proportion increased slightly by the 2013/14 iteration of the survey, when $49 \%$ of respondents indicated that their hospital provided home care services, with $59 \%$ of these programs employing pharmacists with a role in managing medication regimens for complex and highrisk patients. ${ }^{13}$

The 2009/10 and 2013/14 Canadian surveys ${ }^{12,13}$ involved only hospital pharmacy administrators (i.e., did not include community-based practices) and, more importantly, did not ascertain the nature of the in-home services provided by pharmacists. Therefore, the aim of the study reported here was to survey pharmacists in all settings that provide medication-related care to patients in their homes. Its objectives were to identify the services provided, the methods of remuneration, and barriers and facilitators to service provision.

\section{METHODS}

Research ethics approval was obtained from the University of Waterloo Office of Research Ethics.

A web-based survey of Canadian pharmacists was designed, based on survey questions used in the survey conducted in 1999 by MacKeigan and others ${ }^{10}$ and updated to reflect recent changes in pharmacy practice scope and remuneration. Specifically, any questions related to dispensing of medications or home health supplies were removed in order to focus on clinical care, the practice site option of primary care clinic was added, and services related to chronic disease monitoring and management of acute health conditions were added to reflect pharmacists' current scope of practice. Furthermore, facilitators and barriers related to having access to electronic health records and expanded-scope legislation 
were added. Pilot testing was performed by asking 2 pharmacists known to practice in the area to complete the survey and requesting feedback on their interpretation of the questions and answer options presented; the survey was then revised before widespread circulation. The survey was administered by the Survey Research Centre at the University of Waterloo in Waterloo, Ontario.

Survey participants were recruited via multiple channels. First, provincial and national pharmacy associations were contacted and asked to provide a link to the questionnaire in their regular newsletters. A total of 7 provincial associations (in Alberta, Manitoba, Ontario, Quebec, Nova Scotia, Prince Edward Island, and Newfoundland and Labrador) and 2 national associations (the Canadian Pharmacists Association and the CSHP) agreed to participate in this dissemination. An introduction to the study and a web link to the questionnaire were placed in all regularly scheduled member newsletters until the closing date of the survey. Additionally, pharmacists known by the researchers to provide home-based services were contacted directly and encouraged to complete the survey. Information about the study was also posted to social media, including Facebook and Twitter. Finally, those who responded to the survey were given a web address that they were encouraged to forward to colleagues (a method called "snowball sampling"). The survey was open for 8 weeks. Although reminders could not be sent directly to nonrespondents, reminder calls for participation were posted in the association newsletters and to social media. No incentives were offered for completion of the survey.

The web link first directed individuals to a page containing study information. Participants provided explicit consent to participate by clicking a link to continue to the survey questions. Four screening questions had to be answered in the affirmative for a respondent to be invited to complete the remainder of the questionnaire: (1) Are you currently a practising pharmacist? (2) Do you or your pharmacist coworkers at your practice site conduct at least one home visit per week, on average? (3) Are these visits conducted specifically for clinical/consultative purposes beyond routine prescription counselling? (4) Are these visits documented? A negative response to any of these questions indicated that the respondent did not meet the eligibility criteria; in this situation, the survey closed and the participant could not submit any additional information.

The remainder of the questionnaire consisted of 23 questions, 4 of which collected demographic information (sex, years in practice, education completed, and location of practice). The remaining 17 questions elicited information on the following topics:

- Frequency of service: Number of home visits per month and for the same patient within a calendar year; provided as a text response.

- Specific services offered: Selected from a list that included medication reviews, adherence assessments and interventions, drug information for other health professionals or patients/ caregivers, chronic disease monitoring and management, and care for acute needs such as new-onset hypertension or a recent fall; provided as a yes/no response.

- Remuneration obtained: For services with a "yes" answer above, whether a fee was paid for the service and the source of payment, with the following response options:

- Yes, paid directly by the patient

- Yes, paid by a home care agency

- No, provided as part of a salaried staff pharmacist position (e.g., through a hospital, health region, home care agency, or family physician group)

- No payment

- Reason for referral/visit: A list of 9 potential reasons, consisting of nonadherence, regimen complexity, cognitive impairment, suspected adverse drug reaction, recent or upcoming hospital admission, poor self-management of chronic disease, acute health concern, medication review before planned hospital admission, and medication review before annual examination or specialist referral; respondents were asked to rank those they had experienced from $1=$ most frequent reason to $9=$ least frequent reason.

- Evaluative measures used: Selection of all that apply, from the following list: number/type of services provided, descriptive data on patients seen, number/type of drug-related problems, acceptance of recommendations, clinical outcomes, quality-oflife outcomes, health service utilization, economic outcomes, satisfaction of patients and/or other professionals, and a free-form text option.

- Facilitators and barriers: $\mathrm{A}$ list of 8 facilitators of and 13 barriers to home-based care (plus an option for "Other" with free-form description); respondents ranked those that they had experienced as 1 = most influential, 2 = second-most influential, etc.

The survey questionnaire is available from the authors upon request.

Survey responses were analyzed descriptively using SPSS Statistics, version 23 (IBM, Armonk, New York). The response rate could not be calculated because of the predominant use of passive recruitment methods (notices in newsletters, postings on social media, and snowball sampling), which made the total number of Canadian pharmacists exposed to the study information and links unknown. Incomplete responses were handled by weighting adjustment of the denominator to the number of completed responses, as the sample size was not large enough to accommodate imputation methods. When the "Other" option was selected with a description provided, attempts were made to place the response into one of the existing categories or to create a new item for that response.

\section{RESULTS}

The survey was launched on October 20, 2015, and remained open to responses until December 14, 2015. A total of 17 pharmacists completed the survey, taking 25 minutes on 
average. Respondents' demographic characteristics are presented in Table 1. Seven respondents (41\%) reported receiving additional training or certification following completion of their Bachelor of Science in Pharmacy degree. Almost half of respondents $(n=8$, $47 \%$ ) reported having more than 20 years of practice experience, with the majority of respondents $(n=10,59 \%)$ currently practising in a community pharmacy setting. Respondents were largely from Ontario and Alberta (constituting 9 of 12 respondents who provided their province of residence); these are also the 2 provinces that offer government funding to community pharmacies for performing home visits.

A median of 9 home visits (range 4-40) were performed per pharmacy practice in a typical month. Of the 4 practices $(24 \%)$ reporting 30-40 visits per month, 2 were situated within

\section{Table 1. Respondent Characteristics}

\begin{tabular}{|c|c|c|}
\hline \multirow{2}{*}{$\begin{array}{l}\text { Characteristic } \\
\text { Sex }\end{array}$} & \multicolumn{2}{|c|}{$\begin{array}{c}\text { No. (\%) } \\
\text { of Respondents } \\
(n=17)\end{array}$} \\
\hline & & \\
\hline Male & 2 & $(12)$ \\
\hline Female & 9 & (53) \\
\hline Not provided & 6 & (35) \\
\hline \multicolumn{3}{|l|}{ Practice setting* } \\
\hline Community pharmacy & 10 & (59) \\
\hline Consultant practice & 4 & (24) \\
\hline Hospital pharmacy department & 2 & $(12)$ \\
\hline Private home care agency & 2 & $(12)$ \\
\hline Primary care practice & 2 & $(12)$ \\
\hline Specialty outpatient practice & 1 & (6) \\
\hline Government-operated home care service & 1 & (6) \\
\hline \multicolumn{3}{|l|}{ Education or training after BScPharm*† } \\
\hline Residency & 4 & $(24)$ \\
\hline Doctor of Pharmacy (PharmD) degree & 2 & $(12)$ \\
\hline Certified Diabetes Educator & 2 & $(12)$ \\
\hline Certified Geriatric Pharmacist & 2 & $(12)$ \\
\hline Fellowship & 1 & (6) \\
\hline Master's degree & 1 & (6) \\
\hline Doctor of Philosophy (PhD) degree & 1 & (6) \\
\hline Board Certified Pharmacotherapy Specialist & 1 & (6) \\
\hline \multicolumn{3}{|l|}{ Time licensed as a pharmacist } \\
\hline$<5$ years & 1 & (6) \\
\hline $5-10$ years & 0 & \\
\hline $11-20$ years & 2 & $(12)$ \\
\hline$>20$ years & 8 & (47) \\
\hline Not provided & 6 & (35) \\
\hline \multicolumn{3}{|l|}{ Province or territory of practice } \\
\hline Ontario & 5 & $(29)$ \\
\hline Alberta & 4 & (24) \\
\hline British Columbia & 1 & (6) \\
\hline Manitoba & 1 & (6) \\
\hline Saskatchewan & 1 & (6) \\
\hline Not provided & 5 & (29) \\
\hline
\end{tabular}

* Respondents could select more than one response, as applicable.

tOut of the 17 respondents, 7 had one or more additional credentials. independent community pharmacies and 2 within a home care agency/program. Note that to qualify for the survey, pharmacy practices must have conducted at least 1 visit per week on average; therefore, 4 visits per month was the minimum required to enter the survey. This number was reported by 2 respondents.

The most common service provided by respondents was medication review/reconciliation $(n=17,100 \%)$, followed by adherence assessment ( $n=16,94 \%)$, patient and/or caregiver education ( $n=15,88 \%$ ), education and drug information for other health professionals $(n=13,76 \%)$, chronic disease monitoring $(n=12,71 \%)$, and assessment of acute health concerns $(n=10,59 \%)$. None of the respondents or their employers charged patients directly for these services, and only $3(18 \%)$ charged a private home care agency a fee for certain services (adherence assessment, drug information services, and medication reviews, respectively). Three respondents reported that their pharmacy/organization did not receive direct remuneration in any form for its home visit services, whereas 8 respondents provided this care through a salaried employee of a health region, and 5 respondents practised in community pharmacies that received remuneration through a government-funded program for medication reviews in the home, notably the MedsCheck at Home program in Ontario ${ }^{14}$ and the Pharmacy Clinical Services Framework in Alberta, which allows for the provision of a Comprehensive Annual Care Plan or Standard Medication Management Assessment and associated follow-ups in the patient's home. ${ }^{15}$ One respondent practised in multiple settings, each of which offered home visits; this respondent reported being remunerated by a combination of salary from a community pharmacy, fee-for-service payments from a government program, and a fee-for-service contract with a home care agency.

The most frequent reason for patients to receive a home visit from a pharmacist was a complex medication regimen, followed by suspected medication nonadherence, recent hospital admission or emergency department visit, poor self-management of chronic disease, cognitive impairment, a suspected adverse drug reaction or fall, and an acute health concern. Conducting a medication review before a planned hospital admission, specialist appointment, or annual medical examination were reported among the top 3 reasons by only 2 (12\%) respondents and were ranked last by $9(53 \%)$ respondents.

Twelve respondents (71\%) reported collecting service counts or outcome data for home visits, with the most common being descriptive data on the type of patients seen and the number and type of drug-related problems identified, followed by patient or other health care provider satisfaction with the service, proportion of recommendations accepted by prescribers, clinical outcomes, the overall number of services provided, and quality-of-life outcomes and economic outcomes. In addition, one respondent collected data on patients' health service utilization following the home visit, whereas another collected data intermittently on workload and time spent providing the services. 
Among the 11 respondents who completed the questions about barriers to and facilitators of the provision of home visit services, the most influential facilitators identified were referrals from other health professionals and support from management and coworkers. The most influential barriers cited were no or insufficient remuneration and lack of time for completing visits. One respondent described working in a small rural community and doing home visits for patients in great need, so remuneration at this time was not a barrier; however, "if we were required to do more, then remuneration would become an issue. We need to get paid for our time." Two independent community pharmacies and one hospital ranked remuneration as their greatest barrier. Of the 2 independent community pharmacies, one received no funding at all for home visit activities, and the other billed for the service through the Ontario MedsCheck at Home program. ${ }^{14}$ Table 2 summarizes respondents' rankings of facilitators and barriers related to their influence on the practice's home visit service.

Interestingly, 2 practices identified "ability to bill for the service" as their primary facilitator. Both of these were community pharmacies in Ontario. These 2 practices also identified "no or insufficient remuneration" as their primary barrier, which suggests that although receipt of a fee was a major factor in their ability to provide this service, the current fee $(\$ 150$ for an annual review, with no funding for follow-up visits ${ }^{14}$ ) was seen as insufficient.
In contrast, the Alberta framework offers less per annual review (\$60-\$125, depending on patient complexity and the pharmacist's status as a prescriber), but offers $\$ 20-\$ 25$ per follow-up. Of note, follow-up encounters performed either in person or by telephone are eligible for payment. Only 1 practice from Alberta ranked no or insufficient remuneration as a barrier.

\section{DISCUSSION}

Despite a broadened scope of practice for pharmacists ${ }^{16}$ and government funding for pharmacists to provide patient care activities in the home in 2 provinces, ${ }^{14,15}$ the provision of home visits on a regular basis among pharmacy practices in Canada appears to be infrequent. Although no or insufficient remuneration was ranked as the most influential barrier, payment from patients for the service was not requested by any of the surveyed practices, and nearly 1 in 5 respondents reported that their organization received no remuneration at all for these services.

The researchers used multiple mechanisms (both passive and active) to identify practices nationwide that regularly provide in-home care, but the number identified was small. It is uncertain whether this reflects low provision of this service nationally, nonresponse by those who qualified for the survey, or home visit frequency less than once per week (an eligibility criterion to complete the questionnaire). Because of the low number of

Table 2. Facilitators and Barriers in Respondents' Home Care Pharmacy Practice, Ranked by Level of Influence ( $n=11$ Respondents Overall)*

\section{Facilitators}

\begin{tabular}{|c|c|}
\hline Most influential & $\begin{array}{l}\text { Referrals from other health professionals }(2, n=11) \\
\text { Supportive management and coworkers }(2, n=9) \\
\text { Dedicated time for home visits }(3, n=10) \\
\text { Request from patient or caregiver }(4, n=9) \\
\text { Ability to bill for the service }(4, n=7) \\
\text { Access to electronic medical record }(4, n=5) \\
\text { Expanded scope of practice }(4.5, n=8) \\
\text { Standardized documentation forms }(6, n=7)\end{array}$ \\
\hline & Barriers \\
\hline Most influential & $\begin{array}{l}\text { No or insufficient remuneration }(1, n=4) \\
\text { Lack of time for completing visits }(1.5, n=4) \\
\text { Resistance from other health professionals }(2, n=5) \\
\text { Lack of time for travel to patient's home }(2.5, n=2) \\
\text { Lack of time for documentation }(3, n=6) \\
\text { Lack of access to electronic medical record }(3, n=5) \\
\text { Lack of referrals from other health professionals }(3, n=5) \\
\text { Resistance from patients or caregivers }(3, n=3) \\
\text { Obtaining contracts with home care agencies }(3, n=3) \\
\text { Lack of patient or caregiver interest }(4, n=5) \\
\text { Unsupportive management and coworkers }(5, n=1) \\
\text { Limited scope of practice }(7.5, n=2)\end{array}$ \\
\hline Least influential & Lack of training or confidence $(8, n=1)$ \\
\hline
\end{tabular}

*Respondents were instructed to rank the most influential barrier or facilitator as "1", with " 2 " indicating the second-most influential, and so on. Because respondents were asked to rank only those factors that they had personally experienced in practice, not all factor options were ranked by every respondent. For each factor, data are presented as the median rank, followed by the number of respondents who ranked that factor. 
respondents, analysis of the results by subgroups, including sex, years in practice, or location, could not be performed.

Relative to a similar survey conducted in 1999 and published in $2002,{ }^{10}$ the current survey identified a similar number of practices overall (17 in 2015 versus 16 in 1999), with a smaller proportion of respondents practising in a community pharmacy than in other settings (59\% in 2015 versus $75 \%$ in 1999). Considering that $38 \%$ of the 217 respondents to the 2013/14 Hospital Pharmacy in Canada Survey stated that their hospitals provided a home care service, and that $48 \%$ of these hospitalbased services included pharmacists, ${ }^{13}$ the current survey might have been expected to identify as many as 40 practices based in a hospital setting alone. Yet we identified only 17 unique practices across all settings. A number of potential reasons may have played a role, including different survey response rates (the Hospital Pharmacy in Canada Survey had a 78\% response rate) and different definitions of what qualifies as a "regular" home care practice. For example, the survey of hospital administrators may have included care provided to home care patients based on a chart review (rather than an in-home visit) or pharmacist involvement in care for technical purposes, such as set-up of total parenteral nutrition or IV drug therapy. Practices offering these activities alone would not have qualified for our survey.

The findings of this survey have a number of practice implications. First, there appears to be some hesitation, particularly in the community pharmacy sector, to seek adequate remuneration to offset costs to provide home care services. Little progress on this issue appears to have been made in the decade since a 2005 paper on reimbursement for home care pharmacy services issued a national call to action to bill for these services: ${ }^{17}$

If pharmacists do not charge for the pharmaceutical [home] care they provide, they will reduce the perceived value of those services and fail to create the positive image needed to change payers' perceptions and expectations of the profession as a whole.

Still, the current survey found no practices that charged patients for the service, and few that charged home care agencies. While some provinces do offer fee-for-service payments to community pharmacies for this type of patient care service, respondents from those provinces, as well as those from provinces that do not remunerate community pharmacies for these services, cited remuneration as an influential barrier. This finding leads to the second implication, which is the value of the service. Although $71 \%$ of survey respondents reported collecting some type of evaluative data related to these visits, patient demographic statistics and service counts were most frequently determined, with clinical and economic outcomes least frequently documented. It can be argued that the latter factors are key to determining the return on investment for this type of service and are needed to advocate for appropriate remuneration. Without a clear understanding of the organizational costs of providing the service and the benefits to patients and the broader health care system, it is difficult to justify billing patients directly for the service, the adoption of existing remuneration models by other provinces, or the modification of fees to ensure its sustainability. Future research should therefore explore the workload associated with providing these services and the quality of the care provided.

Third, it can be extrapolated that few patients receiving home care receive such visits from pharmacists. Even for patients who are not homebound, the provision of pharmaceutical care in the home may reveal concerns that cannot be identified in a community pharmacy setting. Indeed, this is the hypothesis of a study that is currently under way in Ontario. ${ }^{18}$ Community pharmacists' knowledge of their patients' medication histories can facilitate the proactive identification of those who may benefit from a home visit, such as those taking drugs with a narrow therapeutic index, those with renal or hepatic impairment, and those with complex medication administration regimens. However, respondents to the current survey identified referrals from other health care professionals as the leading facilitator of home visits. A downside to referral-based patient identification is that it may be biased toward identifying patients after they have experienced an adverse consequence of suboptimal medication use. This approach may limit the potential impact that in-home care by pharmacists can have on prevention of chronic disease progression or other medical complications.

Finally, in contrast to existing literature on barriers faced by pharmacists in providing patient care, ${ }^{19,20}$ perceived lack of confidence or skills did not appear to be a key barrier to in-home care among respondents. However, it must be noted that the survey specifically recruited those already providing a home visit service with a frequency of at least once weekly. It is possible that those pharmacists who lack confidence or skills in performing medication management services in the home may choose not to perform those services at all, or do so less frequently than once weekly, and thus would not have qualified for the study. Rather, influential barriers faced by respondents were largely organizational in nature, referring to the context within which such services were to be provided.

A study conducted in an Ontario community pharmacy in 2012 found that revenues from government-funded medication review services (the majority of which were home-based) were sufficient to offset a pharmacist's salary, demonstrating the potential financial feasibility of such services. ${ }^{9}$ Notably, however, the costs associated with travel to patients' homes and support staff time for patient bookings were not considered in that study. To ensure the growth and sustainability of pharmacist home visits, interested pharmacies are encouraged to perform case-finding ${ }^{21}$ to identify those patients who are at risk of adverse medicationrelated outcomes, to charge for this service, and to collect and report clinical, economic, and/or humanistic outcomes. Together, these data can address the evidence gap related to the clinical- and 
cost-effectiveness of pharmacists' in-home care, with the goal of making it available to a greater number of Canadians.

\section{CONCLUSION}

The regular provision of home visits by Canadian pharmacists remains an infrequent practice, with inadequate remuneration and inadequate time to perform the visits within existing workload cited as key barriers. Enhanced documentation and reporting of workload impacts and clinical outcomes will be valuable in efforts to advocate for greater recognition of, and funding for, pharmacist home visit programs.

\section{References}

1. Portraits of home care in Canada. Mississauga (ON): Canadian Home Care Association; 2013.

2. Turcotte M. Canadians with unmet home care needs. Insights on Canadian society. Ottawa (ON): Statistics Canada; 2014 Sep [cited 2017 Mar 18]. Cat no. 75-006-X. Available from: www.statcan.gc.ca/pub/75-006-x/ 2014001/article/14042-eng.pdf

3. Seniors in need, caregivers in distress: what are the home care priorities for seniors in Canada? Toronto (ON): Health Council of Canada; 2012 [cited 2017 Mar 19]. Available from: www.carp.ca/wp-content/uploads/2012/ 04/HCC_HomeCare_2d.pdf

4. Doran DM, Hirdes J, Poss J, Jantzi M, Blais R, Baker GR, et al. Identification of safety outcomes for Canadian home care clients: evidence from the Resident Assessment Instrument - Home Care reporting system concerning emergency room visits. Healthc Q. 2009;12 Spec No. Patient:40-8.

5. Health Quality Ontario. In-home care for optimizing chronic disease management in the community: an evidence-based analysis. Ont Health Technol Assess Ser. 2013 [cited 2017 Mar 18];13(5):1-65. Available from: www.hqontario.ca/Portals/0/Documents/evidence/reports/full-report-inhome-care-ocdm-130906-en.pdf

6. Wong CX, Carson KV, Smith BJ. Home care by outreach nursing for chronic obstructive pulmonary disease. Cochrane Database Syst Rev. 2012;4: CD000994.

7. MacKeigan LD, Nissen LM. Clinical pharmacy services in the home. Dis Manag Health Outcomes. 2008;16(4):227-44.

8. Papastergiou J, Zervas J, Li W, Rajan A. Home medication reviews by community pharmacists: reaching out to homebound patients. Can Pharm J. 2013;146(3):139-42.

9. Riley K. Enhanced medication management services in the community: a win-win proposal from an economic, clinical and humanistic perspective. Can Pharm J. 2013;146(3):162-8.

10. MacKeigan LD, Marshman JA, Kruk-Romanus D, Milovanovic DA, Jackevicius C, Naglie G, et al. Clinical pharmacy services in the home: Canadian case studies. J Am Pharm Assoc. 2002;42(5):735-42.

11. CSHP goals and objectives for pharmacy practice in hospitals and related healthcare settings to be achieved by 2015. Ottawa (ON): Canadian Society of Hospital Pharmacists; 2008 [cited 2016 Mar 19]. Available from: www.cshp.ca/dms/dmsView/2_CSHP-2015-Goals-and-Objectives-Feb25\%2707-w-Appdx-rev-May\%2708.pdf
12. Hospital pharmacy in Canada 2009/2010 report. Hospital Pharmacy in Canada Editorial Board; 2010 [cited 2016 Mar 17]. Available from: www. lillyhospitalsurvey.ca/hpc2/content/2010_report/2009_2010_full_e.pdf

13. Hospital pharmacy in Canada 2013/2014 report. Hospital Pharmacy in Canada Editorial Board; 2014 [cited 2016 Nov 15]. Available from: www. lillyhospitalsurvey.ca/HPC2/Content/2015_report/FULL-2015.pdf

14. MedsCheck at home. Toronto $(\mathrm{ON})$ : Ontario Ministry of Health and Long-Term Care; 2013 [cited 2016 Nov 15]. Available from: www. health.gov.on.ca/en/pro/programs/drugs/medscheck/medscheck_home.aspx

15. Compensation plan for pharmacy services. Edmonton (AB): Alberta Health; 2014 [cited 2016 Nov 15]. Available from: www.rxa.ca/media/187997/ MO-Apr-114-update.pdf

16. Pharmacists' expanded scope of practice. Ottawa $(\mathrm{ON})$ : Canadian Pharmacists Association; 2016 [cited 2017 Jan 29]. Available from: https://www. pharmacists.ca/pharmacy-in-canada/scope-of-practice-canada/

17. Woodend AK, Lawrence JA. Reimbursement for home care pharmacy current status and future strategies. Can Pharm J. 2005;138(4):40-5.

18. CFP funds study of home-based reviews. Mississauga (ON): Canadian Foundation for Pharmacy; 2015 [cited 2017 Jan 29]. Available from: www. cfpnet.ca/en/news/details/id/162

19. Blake KB, Madhavan SS. Perceived barriers to provision of medication therapy management services (MTMS) and the likelihood of a pharmacist to work in a pharmacy that provides MTMS. Ann Pharmacother. 2010; 44(3):424-31.

20. Frankel GEC, Austin Z. Responsibility and confidence: identifying barriers to advanced pharmacy practice. Can Pharm J. 2013;146(3):155-61.

21. Kassamali A, Houle S, Rosenthal M, Tsuyuki RT. Case finding: the missing link in chronic disease management. Can Pharm J. 2011;144(4):170-1.e1.

Sherilyn Houle, BSP, PhD, is an Assistant Professor with the School of Pharmacy, University of Waterloo, Waterloo, Ontario.

Linda MacKeigan, PhD, is an Associate Professor with the Leslie Dan Faculty of Pharmacy, University of Toronto, Toronto, Ontario.

Competing interests: None declared.

\section{Address correspondence to:}

Dr Sherilyn Houle

School of Pharmacy

University of Waterloo

200 University Avenue West

Waterloo ON N2L 3G1

e-mail: sherilyn.houle@uwaterloo.ca

Funding: This work was supported by an Emerging Scholar Mentorship Grant to Sherilyn Houle from the Network for Aging Research at the University of Waterloo. 